\title{
TEAM PERFORMANCE AND EFFICIENCY, TOWARD A CONCEPTUAL FRAMEWORK
}

\author{
Norrin Halilem, Department of Management Laval University, Quebec, Qc, Canada \\ Nabil Amara, Department of Management Laval University, Quebec, Qc, Canada \\ Rejean Landry, Department of Management Laval University, Quebec, Qc, Canada
}

dx.doi.org/10.18374//JBS-13-4.3

\begin{abstract}
Research is knowledge-intensive work, which implies performing complex and ambiguous activities in order to develop or create knowledge. The context of researchers is marked by a few trends: 1) an increasing complexity of research objects, which requires more and more to adopt multidisciplinary approaches; 2) emerging institutional pressures under which the academic career is more and more dependent on scientific researchers' results. Consequently, individuals tend to join teams in order to maximize the cumulative advantage of collaboration on research performance and effectiveness. The last decades have thus shown a significant shift in the way of conducting research, from individual based work to an organization of work in teams of scientists. However, despite the importance of working groups for research, no synthesis of empirical evidence has yet been done on academic researchers. This scoping review allows to advance knowledge on the synthesis of research team performance and effectiveness and to construct an evidence-based conceptual framework. It allows to identify 28 articles, whose analysis lead to the identification of more than 15 groups of operational definitions of performance and effectiveness, and more than 25 groups of determinants linked to three levels of aggregation (project, team, and institutional/organizational levels).
\end{abstract}

Keywords: TEAM, GROUP, PERFORMANCE, EFFICIENCY, SCOPING REVIEW 